\title{
Aircraft System Noise Assessment of the NASA D8 Subsonic Transport Concept
}

\author{
Ian A. Clark* and Russell H. Thomas ${ }^{\dagger}$ \\ NASA Langley Research Center, Hampton, VA 23681 USA \\ Yueping Guo \\ NEAT Consulting, Seal Beach, CA 90740 USA
}

\begin{abstract}
A vehicle-level noise assessment has been performed for the NASA D8 concept aircraft (ND8) in the NASA Advanced Air Transport Technology Project portfolio. The NASA research-level Aircraft NOise Prediction Program (ANOPP-Research) was used to predict the noise from each source component on the ND8 to build up a noise estimate for the full aircraft. The propulsion airframe aeroacoustic (PAA) effects of the ND8, namely boundary layer ingestion (BLI) with its influence on fan noise, and the noise shielding, reflection, and diffraction mechanisms of the unconventional airframe, were empirically modeled using experimental data. Noise reduction technologies appropriate to the 2025-2035 time frame were included in this study. Including all technologies and PAA effects, the ND8 is predicted to have a cumulative margin to the Stage 4 certification metric of only 7.4 EPNdB. Boundary layer ingestion is predicted to have a detrimental impact on cumulative noise levels on the order of 15 EPNdB. Fan noise is seen to be the primary noise source at all three certification points, even if the BLI noise impact could be entirely suppressed. The impact of engine noise shielding by the airframe is limited by a lack of aft shielding and the presence of horizontal tail reflections in the aft direction. The physical constraint on engine size by the pi-tail is seen as a potential barrier to engine noise reduction through the corresponding limitation on fan bypass ratio. Mildly reduced climb performance (compared to similar reference aircraft) does not provide any benefit through increased noise propagation distance. If the boundary layer ingestion noise penalty could be suppressed such that BLI would have no effect on noise, the cumulative margin to Stage 4 would increase to 22.4 EPNdB, still below the NASA Mid Term goal of 32-42 EPNdB.
\end{abstract}

\section{Introduction}

$\mathrm{T}$ HE NASA Advanced Air Transport Technology (AATT) Project is aimed at the development and demonstration of advanced technologies for aircraft systems that could meet aggressive goals for fuel burn, noise, and emissions. In the Mid Term time frame (2025-2035), the fuel burn reduction goal is 50-60\% relative to a best-in-class 2005 aircraft, and the noise goal is 32-42 EPNL dB (Effective Perceived Noise Level) cumulative below the Stage 4 FAA noise requirement; the emission goal is a reduction of $80 \%$ in NOx (oxides of nitrogen) levels below the CAEP 6 (Committee on Aviation Environmental Protection) standard. The AATT project seeks to develop key, enabling technologies to a TRL of 4-6 by the target date. As one of five concept aircraft in the AATT portfolio, the NASA D8 (ND8) has been proposed as a potential candidate that could meet these aggressive goals by incorporating an unconventional airframe configuration (Figure 1). The NASA D8 concept is based on the Massachusetts Institute of Technology (MIT)/Aurora Flight Sciences D8 aircraft first developed under a 2008 NASA Research Announcement [1] and later updated by Drela [2]. Yutko et al. [3] undertook a comprehensive conceptual design of the MIT/Aurora D8. The AATT project has independently evaluated the D8 concept for several years. The designation NASA D8 (ND8) was developed to differentiate the NASA model of the D8 from the MIT/Aurora D8 model, since different tools and assumptions were used to develop the models. The ND8 was developed primarily as a technology collector for AATT to serve as a platform to assess the incremental benefits of including certain technologies on an airframe. In this sense, the ND8 is not designed to compete with any existing or future aircraft, but rather is designed to resemble the overall D8 concept

\footnotetext{
*Research Aerospace Engineer, Aeroacoustics Branch, MS 461, AIAA Member, ian.a.clark@ nasa.gov.

${ }^{\dagger}$ Senior Research Engineer, Aeroacoustics Branch, MS 461, AIAA Associate Fellow.

$\ddagger$ NEAT Consulting, 3830 Daisy Circle, AIAA Associate Fellow.
} 
with details provided by NASA tools and models for aircraft design, analysis, and optimization. More details of the ND8 design are given in Section III.

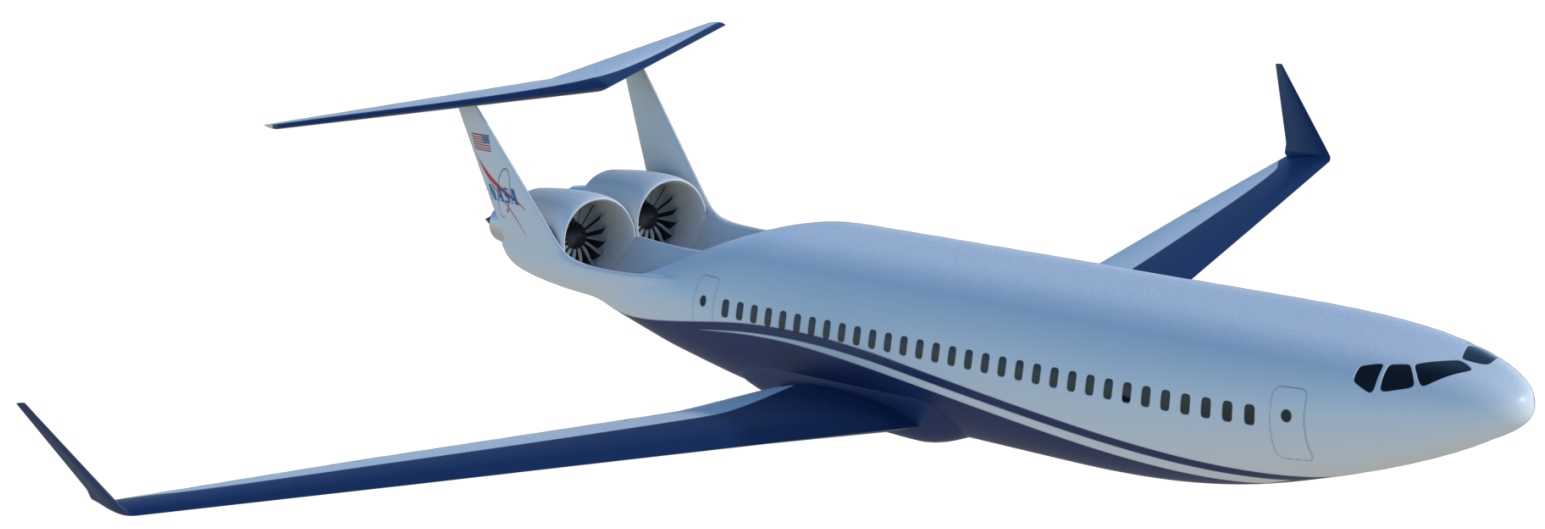

Fig. 1 Artist rendering of the NASA D8 subsonic transport concept.

The combined fuel consumption, emissions, and noise goals of AATT will likely require a change in aircraft configuration from the traditional "tube and wing" design that has persisted throughout many years of advancements in technology, structures, materials, and aerodynamic design [4]. The cylindrical fuselage provides an effective pressure vessel to resist pressure loading of the cabin while flying at high altitudes. A noncylindrical fuselage experiences additional stresses and bending moments while under pressure, which necessitates structural reinforcements that can be heavy and expensive. The ND8 features a twin-aisle lifting body fuselage [3]. This "double-bubble" design retains a similar load path through the fuselage structure by using two partial cylinders braced with faired tension rods in the cabin [5]. This design enables a wide fuselage, which leads to increased passenger capacity, faster boarding times, and a certain amount of lift generated by the fuselage. The lift generated by the fuselage has several impacts on the design of the airframe, namely the reduction of wing area in proportion to the size of the fuselage, and a decrease of horizontal tail area due to the increased lift acting near the front of the aircraft, which contributes a positive pitching moment [3].

The ND8 concept calls for placement of the engines at the aft dorsal location on the fuselage to take advantage of fuel savings arising from boundary layer ingestion (BLI). The ND8 ingests the boundary layer moving over the top of the fuselage - about $40 \%$ of the total fuselage boundary layer [6]. BLI leads to increased propulsive efficiency by reducing the flow velocity differential between the propulsive airstream and the free stream flow, compared to a traditional configuration of engines under the wing [6]. Much work has been done on the aerodynamic impact of such a design $[6,7]$ and in designing an "inflow-distortion-tolerant" fan, but the acoustic impact of this configuration has not been wholly addressed. De la Rosa Blanco and Hileman [8] published a system level noise assessment of the Aurora Flight Sciences/MIT D8 design using correlations that were self-programmed based on documentation of the NASA Aircraft NOise Prediction Program (ANOPP). The use of self-programmed noise models that were intended for conventional tube-and-wing aircraft yields high uncertainty for this noise prediction of an unconventional configuration. The effect of incorporating boundary layer ingestion was limited to increased shielding with the engines placed at the aft dorsal location. A full conceptual design of the Aurora/MIT D8 also featured a noise assessment [3]. Boundary layer ingestion was incorporated into the design, and noise was predicted with and without this feature. The configuration change to shift the engines from the underwing location (no BLI) to the aft dorsal location (to enable BLI) is reported to provide a noise reduction of approximately $7 \mathrm{EPNdB}$ on a system level. It is assumed by the authors of this study that Yutko et al. [3] computed the acoustic BLI effect considering only the system benefits associated with reduced engine requirements, reduced weight, and favorable placement of the engines above the fuselage to take advantage of noise shielding. Prior experiments have shown that boundary layer ingestion, and inflow distortion in general, leads to significantly increased fan noise due to unsteady loading of the fan blades [9-11]. Therefore, a complete, credible noise prediction must include all positive and negative propulsion airframe aeroacoustic (PAA) effects: boundary layer ingestion, shielding, reflection, and diffraction.

In support of the NASA goal to quantify the expected noise benefit from unconventional configurations in the AATT portfolio, this work presents a system level noise assessment of the proposed ND8, which may give insight into the 
noise characteristics of a D8 vision system. It is the goal of this study to quantify and account for all aspects of the ND8 design that potentially impact its acoustic performance, including the aforementioned PAA effects. All relevant features of the design will be incorporated into the prediction, including noise from the high lift system, landing gear, wings, pi-tail, engine fan, engine core, and jet, along with the PAA effects on engine noise sources.

\section{Noise Prediction Framework}

The NASA Aircraft NOise Prediction Program (ANOPP) provides the framework for the current noise prediction study. The models and methods contained in ANOPP are under continuous development, and the research-version code used in this study contains several models not present in the released version of ANOPP. The methodology adopted over the last several years during the Environmentally Responsible Aviation (ERA) project places heavy emphasis on the use of relevant experimental data and physics-based analytical methods, which are compatible with complex, unconventional aircraft. This is reflected in the addition of the GUO-LG [12], GUO-FLAP, and GUO-LE [13] modules. The current publicly-available version of ANOPP features mainly empirical or semi-empirical relations, which are more suited to conventional aircraft design philosophies. The progression and development of the noise prediction process during the ERA project is discussed in detail in Thomas et al. [14]. An additional key advancement in recent years has been the ability to directly predict PAA effects, including engine noise shielding and reflection effects of the airframe, using experimental databases and unique data processing tools. This will be discussed further in Section IV.B.

Figure 2 shows the overall noise prediction process and methods. A noise prediction begins with detailed information about the aircraft geometry, engine design and performance, and flight path. Several experimental datasets contribute to the design of the aircraft, as well as the noise source definitions. Integrated Technology Demonstration efforts, summarized by Nickol and Haller [15], were undertaken during the last three years of the ERA project, and those results are used to inform the models for advanced technologies associated with vehicles in the AATT portfolio, including the ND8. Each noise source is predicted individually and follows the flight path for each certification point, which

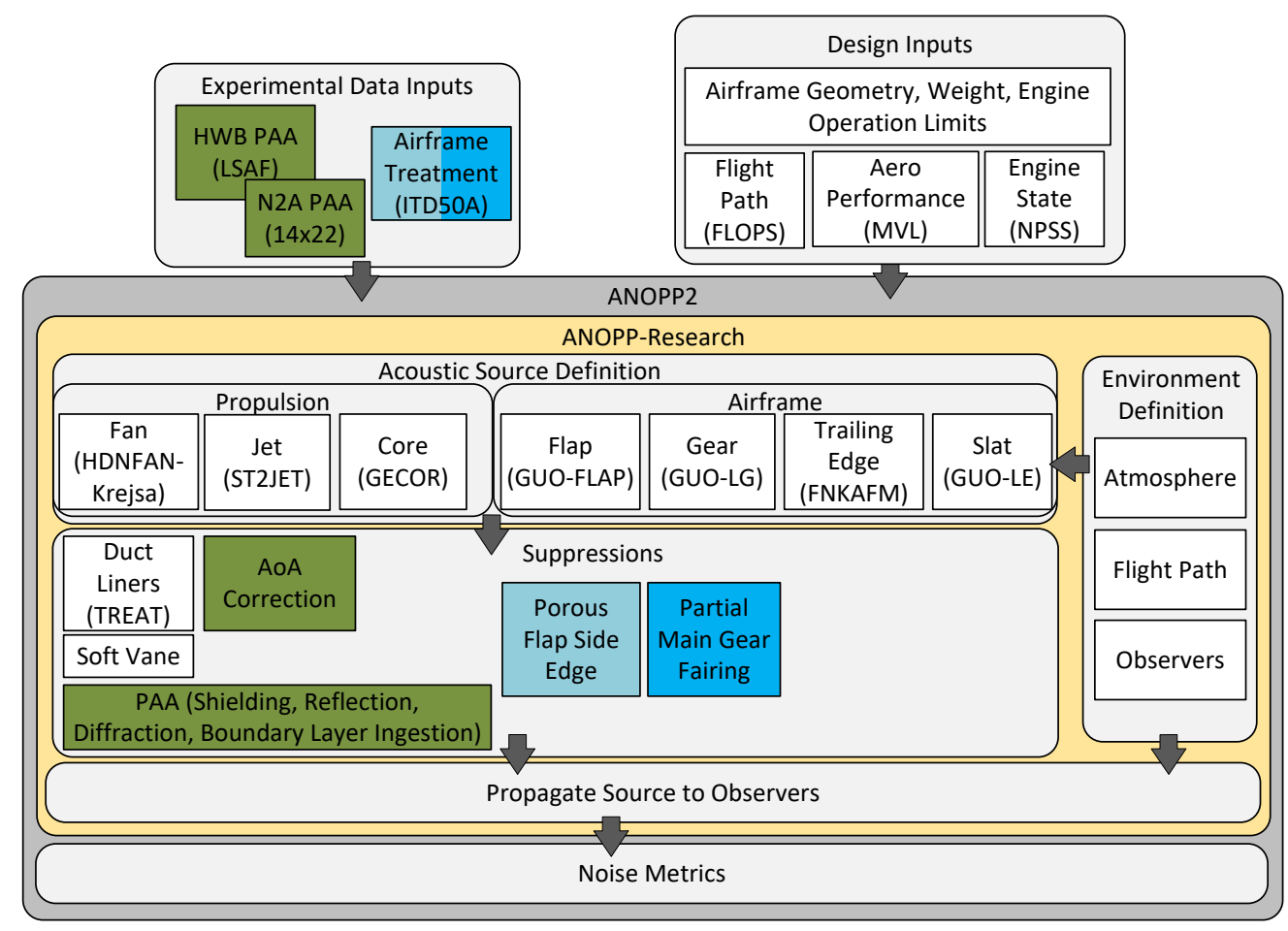

Fig. 2 Overview of the ND8 prediction process used in the current study. ANOPP-Research is used within the ANOPP2 framework. The noise prediction is informed by the ND8 design definition and by experimental data to quantify the PAA effects. 
is determined by the unique aircraft design. PAA effects are evaluated for each engine source before the noise is propagated through the atmosphere to ground observers. ANOPP provides one-third octave band spectra for each source and observer time as the aircraft flies overhead.

The final result of a noise prediction is the cumulative noise metric, described in overview in Figure 3 . The noise metrics used for all predictions are identical to those defined by the Code of Federal Regulations (CFR) Title 14, Part 36. In order to obtain Federal Aviation Administration (FAA) certification to fly, the noise of an aircraft may not exceed certain noise levels defined using the Effective Perceived Noise Level (EPNL), as measured by following the guidelines in Part 36. Noise metrics must be met for the approach, lateral, and flyover locations, which correspond to the stages of flight with the greatest noise impact on communities surrounding airports. These same metrics are used to evaluate future aircraft and noise reduction concepts in order to quantify their value on a system level using accepted standards. Noise predictions are performed at each certification point, resulting in individual EPNLs, which are then combined to arrive at the cumulative EPNL. The latest Part 36 standard for certification is termed Stage 5, which defines the maximum allowed cumulative EPNL as a function of aircraft weight and the number of engines. However, the NASA noise goals referenced in this and previous publications are written in reference to Stage 4 certification levels. For the advanced aircraft and noise reduction technologies evaluated in this study, the certification levels are reported as margins below Stage 4 to clearly define the benefit of these concepts in terms of NASA goals and in relation to existing technologies.

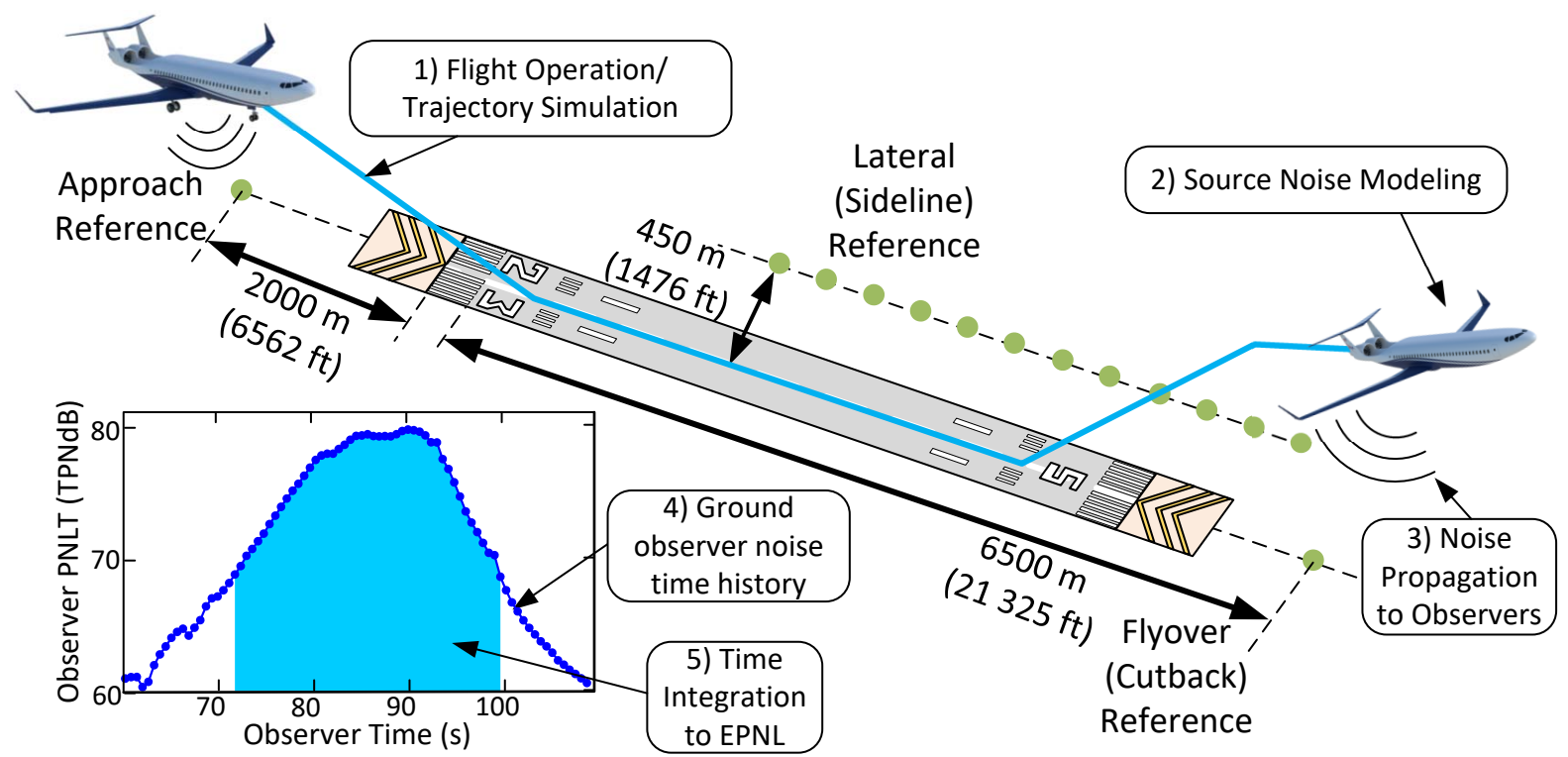

Fig. 3 Noise certification points with prediction methodology.

\section{ND8 Design}

The ND8 was designed to carry 180 passengers a distance of 3000 nautical miles, with a cruise Mach number and altitude of 0.785 and 37,000 feet, respectively. The design balanced field length was 8000 feet. This mission is similar to that of the Boeing 737-800, which serves as the reference vehicle to the ND8. The aircraft design and sizing were performed by Marien et al. [6], and overall weight and size parameters are given in Table 1. As mentioned previously, the ND8 was not designed as a vision system to compete with any current or future aircraft, but rather to complete the given mission while retaining the overall configuration and features of the MIT/Aurora D8. The design optimization was set up to minimize block fuel for the design mission. As such, the ND8 was not optimized for noise reduction. Advanced aerodynamics, materials, and propulsion system assumptions were made consistent with a 2035 entry-into-service date. Tools for the vehicle design included the NASA Flight Optimization System (FLOPS) and Numerical Propulsion System 
Simulation (NPSS). A rendering showing the design elements of the ND8 is shown in Figure 4.

Table 1 ND8 overall weight and size parameters.

\begin{tabular}{lc}
\hline Takeoff Gross Weight & $141610 \mathrm{lb}$ \\
Wing chord (max) & $14.7 \mathrm{ft}$ \\
Wing chord (min) & $5.1 \mathrm{ft}$ \\
Wingspan & $118.2 \mathrm{ft}$ \\
Wing Leading Edge Sweep Angle & $24 \mathrm{deg}$ \\
Fuselage Length & $106 \mathrm{ft}$ \\
Fuselage Width & $17.2 \mathrm{ft}$ \\
Fuselage Height & $12.4 \mathrm{ft}$ \\
\hline
\end{tabular}

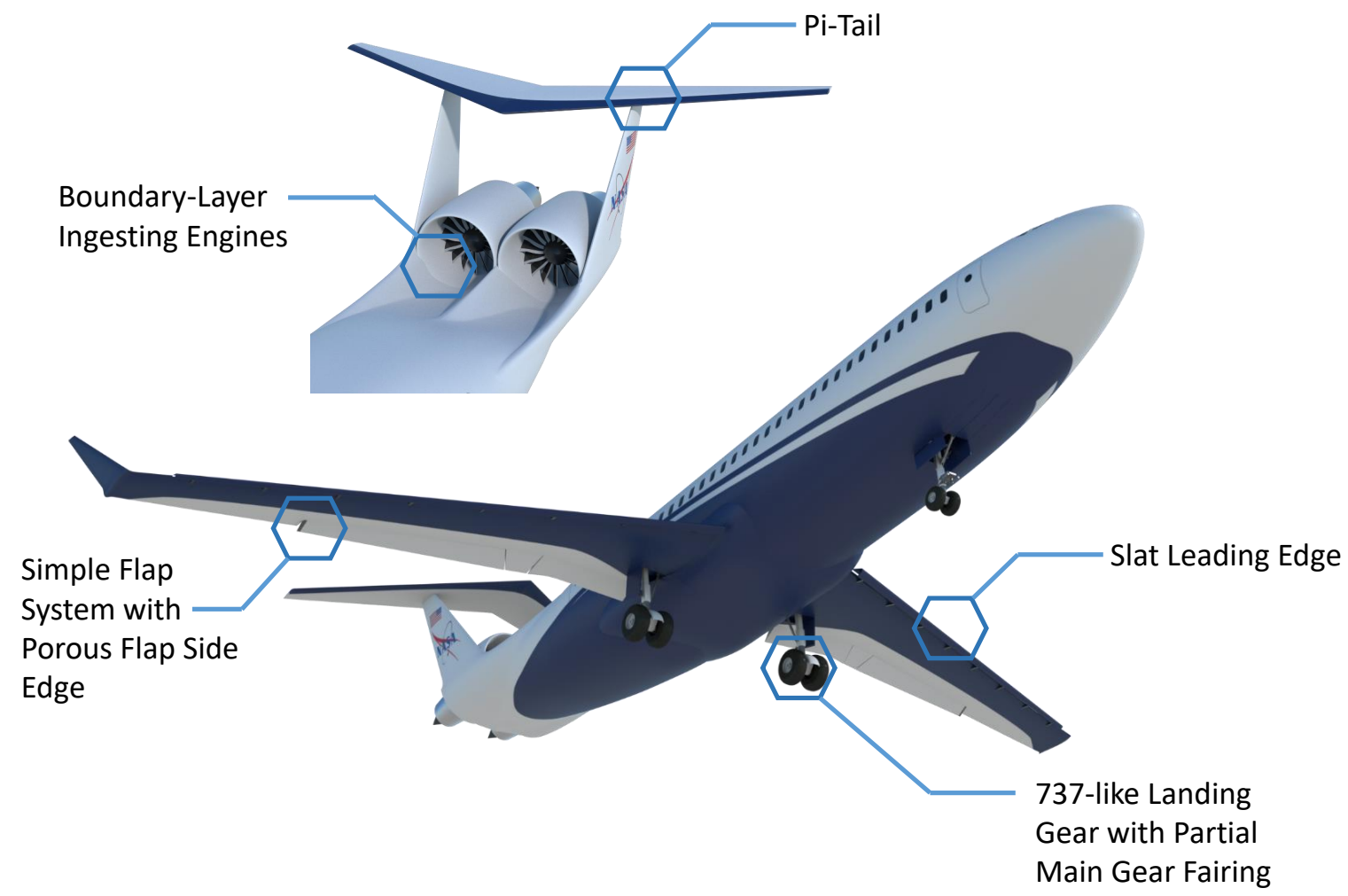

Fig. 4 Design elements of the ND8 concept, with closeup view of tail section (inset).

Several assumptions and aspects of the design process are relevant to noise and so will be highlighted here. The baseline engine architecture of the ND8 calls for dual two-spool geared turbofan engines mounted within the pi-tail at the aft dorsal location on the fuselage. It is noted here that this configuration is a departure from the MIT/Aurora D8, which features a reverse-flow core that is mechanically linked to the fan through a gearbox [3] in order to satisfy the 1:20 rule set by the FAA [16]. Since the ND8 is a technology collector for AATT, and is not intended to meet all FAA airworthiness certification criteria, the engines are mounted in this way for the present analysis. An important aspect of the engine design relates to the physical size constraints of the geared turbofan engines. Because the ND8 configuration dictates that the engines are placed within the pi-tail, the maximum fan diameter is limited to $1.82 \mathrm{~m} \mathrm{(72}$ inches). To meet climb performance metrics, the fan pressure ratio (FPR) is varied to provide enough thrust for a given 
fan diameter. The engine core is constrained to a minimum size, which reflects the expected physical limitations of core technology in the 2035 time frame [6]. The final design of the ND8 engine calls for a fan pressure ratio of 1.35 and a bypass ratio of 16 at takeoff conditions. This design is beyond the current state-of-the-art engines with maximum bypass ratios around 12, but significantly less aggressive than the geared turbofan engines designed for other advanced aircraft concepts with bypass ratios around 25 [14, 15, 17]. Other aspects of the ND8 engine are given in Table 2 and compared to a similar engine-under-wing aircraft from ERA [15], the 160-passenger tube-and-wing aircraft (T+W160). Key differences include the lower bypass ratio and higher tip speed of the ND8 engine, which lead to higher noise source levels. Multiple-degree of freedom acoustic liners are applied to the ND8 engine using the specified duct length and height from the NPSS engine definition. An interstage liner is included with an effectiveness of 50\%, consistent with prior studies [14]. The effects of soft vane liner technology along with sweep and lean of the stator vanes are included in the modeling of fan noise.

Table 2 ND8 engine parameters and takeoff (TO) conditions compared to the T+W160 engine from the ERA Project [15].

\begin{tabular}{lcc}
\hline & ND8 & T+W160 \\
\cline { 2 - 3 } Fan diameter (ft) & 5.9 & 7.0 \\
Number of fan blades & 18 & 18 \\
Number of fan stator vanes & 40 & 40 \\
Normalized rotor-stator spacing & 1.52 & 1.52 \\
Fan pressure ratio at TO & 1.35 & 1.23 \\
Bypass ratio at TO & 16.0 & 25.5 \\
Net thrust at TO (lb) & 15,900 & 16,700 \\
Fan RPM at TO & 3670 & 2640 \\
Fan tip Mach at TO & 1.02 & 0.88 \\
Aft duct liner L/H & 1.95 & 1.83 \\
Inlet duct liner L/R & 0.96 & 0.68 \\
Interstage liner effective L/H & 0.34 & 0.27 \\
\hline
\end{tabular}

The high-lift system of the ND8 consists of a conventional slat leading edge device and a single element flap trailing edge device. The trailing edge flap configuration minimizes discontinuities between flap elements, a design element featured on modern commercial airliners. This leads to a significant reduction in flap-side-edge noise compared to the reference aircraft (Boeing 737-800). In addition, the effect of porous flap side edge technology [18] is included in flap noise modeling, consistent with prior studies [14]. Flight-condition-specific parameters for the high-lift system (flap deflection angles, etc.) are used for noise predictions at each stage of flight. The landing gear consist of a 737-type tricycle gear system with two wheels per main gear and nose gear. A partial main gear fairing $[18,19]$ is included in the modeling of main gear noise consistent with prior studies [14].

In aircraft noise assessment, the flight profile plays a critical role since Mach number and angle of attack determine airframe noise source levels, and the flight path controls noise propagation distance to observers. Takeoff flight path information for the ND8 and two other aircraft, the T+W160 and a 737-like aircraft, are shown in Figure 5, and additional parameters are given in Table 3. The reduced thrust requirements at cruise due to boundary layer ingestion lead to reduced climb performance at takeoff compared to the reference aircraft. As a result, the ND8 is projected to reach an altitude 100 feet lower than a 737 -like aircraft at the cutback certification point (21,325 feet downrange of brake release). This small difference is expected to have a minimal impact on certification noise, but is a departure from other concept aircraft of a similar size which are expected to climb nearly 200 feet above the 737-like aircraft at the cutback point [17]. Aircraft speed at each of the three points also plays a role in total certification noise. The slower speed of the ND8 compared with other aircraft may lead to reduced source noise of airframe components, but is unlikely to have an effect on engine noise source levels. In fact, a slower flight speed is detrimental if the aircraft is engine-noise dominant, as slower speeds lead to longer integration times in the EPNL calculation. 

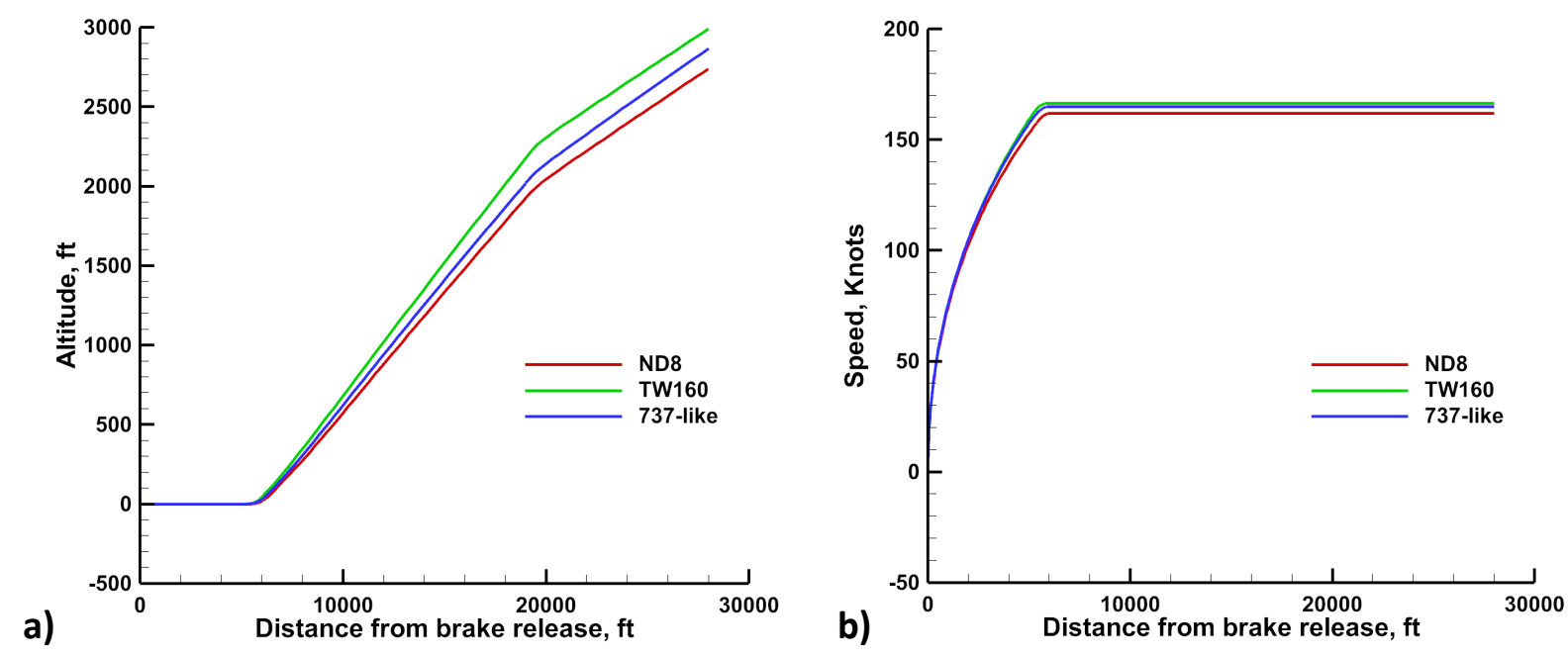

Fig. 5 a) Flight path and b) speed schedule of the ND8, T+W160, and 737-like aircraft.

Table 3 ND8 flight path parameters compared to those of the T+W160 and 737-like aircraft.

\begin{tabular}{cccccc}
\hline & & Climb Angle (deg) & Angle of Attack (deg) & Thrust Fraction & Speed (knots) \\
\hline \multirow{3}{*}{ Approach } & ND8 & -3.0 & 7.7 & 0.17 & 145 \\
& T+W160 & -3.0 & 6.1 & 0.19 & 149 \\
& $737-$ like & -3.0 & 6.5 & 0.12 & 149 \\
\hline \multirow{3}{*}{ Sideline } & ND8 & 8.6 & 6.8 & 1.00 & 162 \\
& T+W160 & 9.5 & 6.6 & 1.00 & 167 \\
& 737-like & 9.0 & 6.9 & 1.00 & 165 \\
\hline \multirow{3}{*}{ Cutback } & ND8 & 5.0 & 7.4 & 0.75 & 162 \\
& T+W160 & 4.9 & 7.3 & 0.68 & 167 \\
& 737-like & 5.3 & 7.6 & 0.76 & 165 \\
\hline
\end{tabular}

\section{ND8 Noise Considerations}

The majority of features on the ND8 will be predicted using the methods available in ANOPP-Research as described in Section II. However, there are several unique features of the ND8 that require special attention along with the development of new methods to reasonably predict the flight noise at a system level. The first feature is boundary layer ingestion, which describes the inflow of slow-moving, turbulent air close to the fuselage into the engine that results in unsteady fan blade loading and increased fan noise. The second feature is the placement of the engines on top and at the rear of the fuselage within the pi-tail, which leads to engine noise shielding by the fuselage and vertical stabilizers, but potential noise reflections by the horizontal stabilizer along with diffraction around the edges of the airframe. The methodology for treating each of these features is now described. To develop a noise model for boundary layer ingestion, three options were identified to predict the effect on fan noise. The use of analytical, numerical, and empirical tools were all considered.

\section{A. Boundary Layer Ingestion Modeling}

Analytical methods have been developed to describe the aeroacoustic effects of turbulence ingestion into rotors and fans. Majumdar and Peake [20] provide a theoretical model for the effect of turbulence ingestion into a fan, and results are given for the ingestion of atmospheric turbulence at static and flight conditions. Further use of this theory would require knowledge of the ingested turbulent velocity spectrum. The theory of Glegg et al. [21] is a time-domain 
approach, which eliminates modeling of the turbulence spectrum, but requires measurements of the four-dimensional inhomogeneous velocity correlation function. For the present study, it was determined that the lack of detailed flow field information prevented the use of rigorous analytical methods.

Numerical methods have the potential to capture the relevant physics to reasonably predict BLI noise. Envia [22] describes a simulation that uses 3D linearized Euler analysis to calculate the acoustic transmission of tonal noise through a fan. The simulation was performed using the NASA code LINFLUX [23]. For the study, the source of the tonal noise was the interaction between the wakes of the fan rotor blades with the outlet guide vanes (OGVs) of the NASA/Pratt and Whitney 22-inch Advanced Ducted Propulsor (ADP). The Euler model was a general inviscid formulation of the interaction between vortical, acoustic, or entropic perturbations with a row of turbomachinery blades. The computational methodology treated the problem in two separate steps. First the acoustic response of the OGV to the rotor wake was computed. Then, the model was used to predict the transmission of the resulting acoustic field through the rotor blades. Simulation results showed good agreement with experimental noise measurements, and clearly identified the need to account for rotor interactions when tracking tonal noise from the OGVs.

This simulation toolset LINFLUX provides a framework by which boundary layer ingestion could be modeled by direct input of the expected distortion field. Although the capability was designed particularly for rotor/stator interaction, the inflow distortion could be thought of as coming from some object upstream of the rotor. By directly defining the Fourier coefficients of the distortion field, the model can calculate the response of the moving rotor blades as it does with the OGVs of the previous study. The acoustic field would then be propagated upstream and to the surrounding domain to determine far field noise. This methodology was considered as a strong candidate for the present study, but the significant time required in both setting up and running the simulation, along with the lack of information on the expected distortion field, meant that this could not be completed in time for the present study, and so remains for future work.

To the authors' knowledge, a comprehensive experiment in which noise is measured from a turbofan ingesting a thick $(\sim 100 \%$ blade span $[7,24])$ turbulent boundary layer has not been performed. As analytical and numerical methods have been ruled out from this investigation, the most promising way forward is to consider the physics of boundary layer ingestion, break down the phenomenon into its constituent components, and define the acoustic effect of each component using data from relevant experiments. This process is shown in conceptual form in Figure 6. The overall physics of boundary layer ingestion is broken up into two parts - the ingestion of turbulence into the fan face, and the once-per-revolution change in angle of attack of the fan blades due to the decreased mean flow velocity entering the lower portion of the engine inlet. Turbulence ingestion is expected to have both a broadband and tone effect on fan
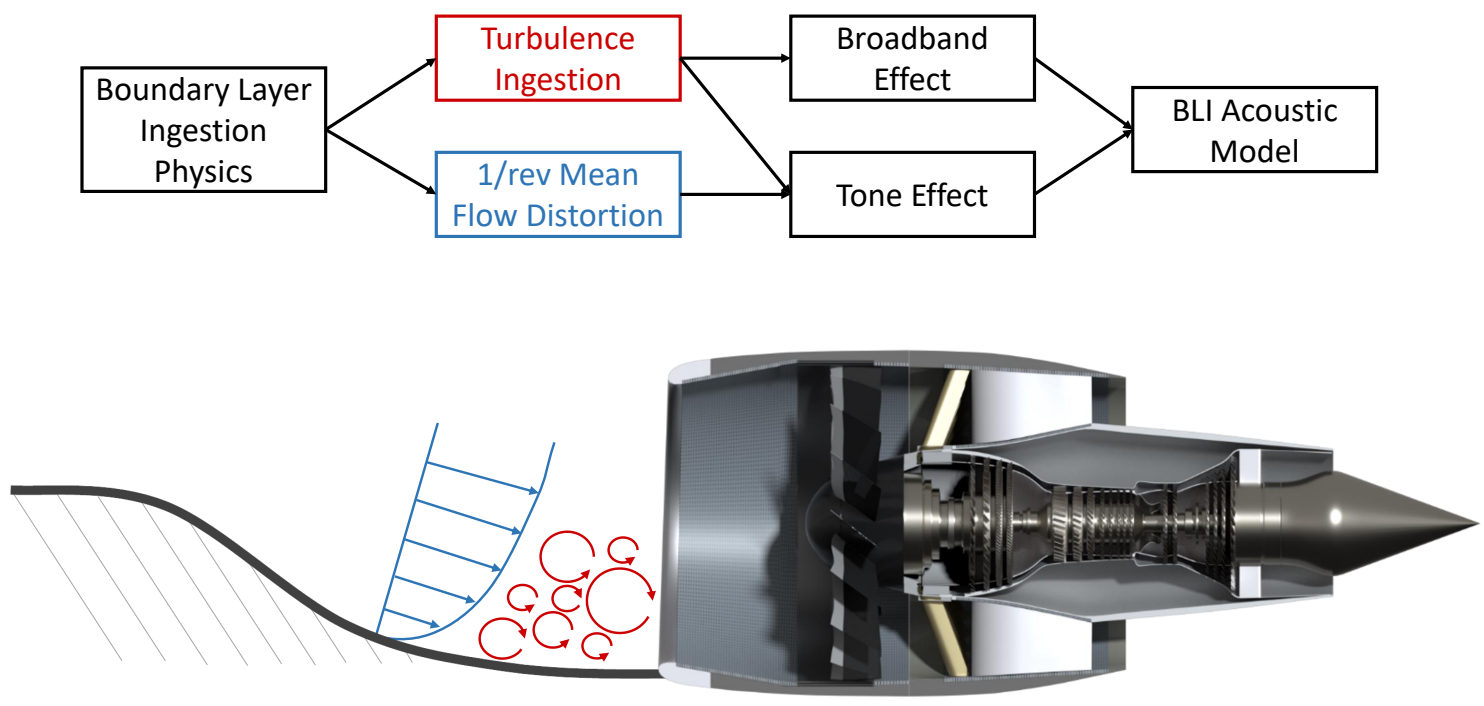

Fig. 6 Acoustic modeling process for boundary layer ingestion, and artist rendering of the ND8 engine with upstream boundary layer. 
noise. The broadband effect is expected due to the unsteady random nature of boundary layer turbulence, while the tonal component arises because this turbulence can be stretched as it is drawn into the engine and cut multiple times by successive fan blades leading to tones at the blade passage frequency and harmonics. The change in blade incidence angle is expected to have only a tone effect, as the fan blades experience a change in loading over regular intervals as they pass through the region of slower-moving fluid. Combining these effects leads to a BLI model that can be applied to fan noise.

\section{Turbulence Ingestion}

Turbulence ingestion has been a subject of active research for many years. One of the first breakthrough studies was published by Hanson [25], wherein it was found that the additional noise observed in static engine tests was due to the ingestion of stretched atmospheric turbulence. This led to the development of inflow control devices (ICDs) for static engine tests. During the development of these devices, many acoustic experiments were performed which measured noise from static engines with and without ICDs in order to quantify their effectiveness. These experiments provide a useful database of noise measurements with and without turbulence ingestion from which we can build an acoustic model.

Jones et al. [26] describe noise measurements of a static JT15D engine mated with two separate ICD designs - one internal to the engine inlet, and one external. Their results indicated that both ICDs led to significantly smoother inflow indicated by a sharp reduction in BPF tones. However, the internal ICD was seen to alter the acoustic propagation behavior of the inlet duct, while the external ICD was largely acoustically transparent. This was determined by placing rods in the inlet to create flow distortions and strong BPF tones which would dominate those from any natural atmospheric inflow distortion. The addition of rods to the inlet led to increases in BPF tones of up to $15 \mathrm{~dB}$, which propagated cleanly through the external ICD but were attenuated by the internal ICD. Without rods, the external ICD was observed to reduce the BPF tone level by up to $10 \mathrm{~dB}$ over a wide range of polar angles due to the removal of inflow distortions caused by atmospheric turbulence.

Preisser and Chestnutt [9] describe flight tests of a JT15D meant to eliminate all effects of inflow distortion and to compare with earlier results. The engine was attached to a Grumman OV-1 aircraft and flown past a series of 30-ft pole microphones. Their results indicated that the inflow control devices tested previously led to a good representation of the measured BPF levels in flight. They also present results for broadband noise levels at static conditions and in flight, taken as the spectral level at the base of the BPF peaks. They show a significant influence of inflow distortion on broadband noise, up to $6 \mathrm{~dB}$ across a wide range of polar angles. This study represents the best comparison of results from this project, and so greatly informs the turbulence ingestion model for the present study.

The results of Preisser and Chestnutt for a static fan with subsonic blade tip speeds with and without an ICD, along with the results of Jones et al. [26] and supplementary flight test results [27] have been used to build a general prediction of this effect on the blade passage frequency tone as shown in Figure 7a. Most of the noise from turbulence ingestion is radiated at a ninety degree angle to the inlet direction, which corresponds to the nearest point of an aircraft flyover, and so is likely to strongly influence system noise. The results of Preisser and Chestnutt are also used to build a prediction of the effect of turbulence ingestion on broadband noise, as seen in Figure 7b. In contrast to the tonal noise, the broadband noise is seen to radiate primarily in the upstream and downstream directions.

With these models in hand, it is useful to compare with other experiments, certain aspects of which make their results unsuitable for model development, but which may still serve as a qualitative check on the general aspects of the model. Clark et al. [28] tested a 10\% scale model of the Pratt and Whitney Advanced Ducted Propeller (ADP) with several inlet shapes (short, long, scarfed, and elliptical) in the NASA Langley 14- by 22-Foot Subsonic Tunnel. The different inlet shapes caused nonuniformity of the inlet boundary layer thickness that led to unsteady forces on the fan that propagated as increased fan noise over the entire acoustic measurement region. Spatially integrated SPL levels indicated that the variation in boundary layer thickness dominated over any noise benefit obtained from varying the inlet shape, and that even small changes in boundary layer thickness resulted in increased tonal levels for the 1-, 2-, and 3-BPF tones of up to $7 \mathrm{~dB}$. Considering the maximum change in boundary layer thickness for this test was between 1.5 and $4.2 \%$ blade span, compared with the nearly $100 \%$ blade span boundary layer thickness expected for the ND8 with BLI, the relative magnitude of the model for the present study is considered reasonable.

Koch [29] conducted a series of studies using the Advanced Noise Control Fan (ANCF) at the NASA Glenn Research Center. Several configurations of cylindrical rods were placed just upstream of the fan to produce a distortion pattern over the fan face. Acoustic measurements were made in the anechoic test facility surrounding the static fan rig, and the results indicated an increase in both tonal and broadband noise. Measured tonal levels increased by 20-25 dB nearly 

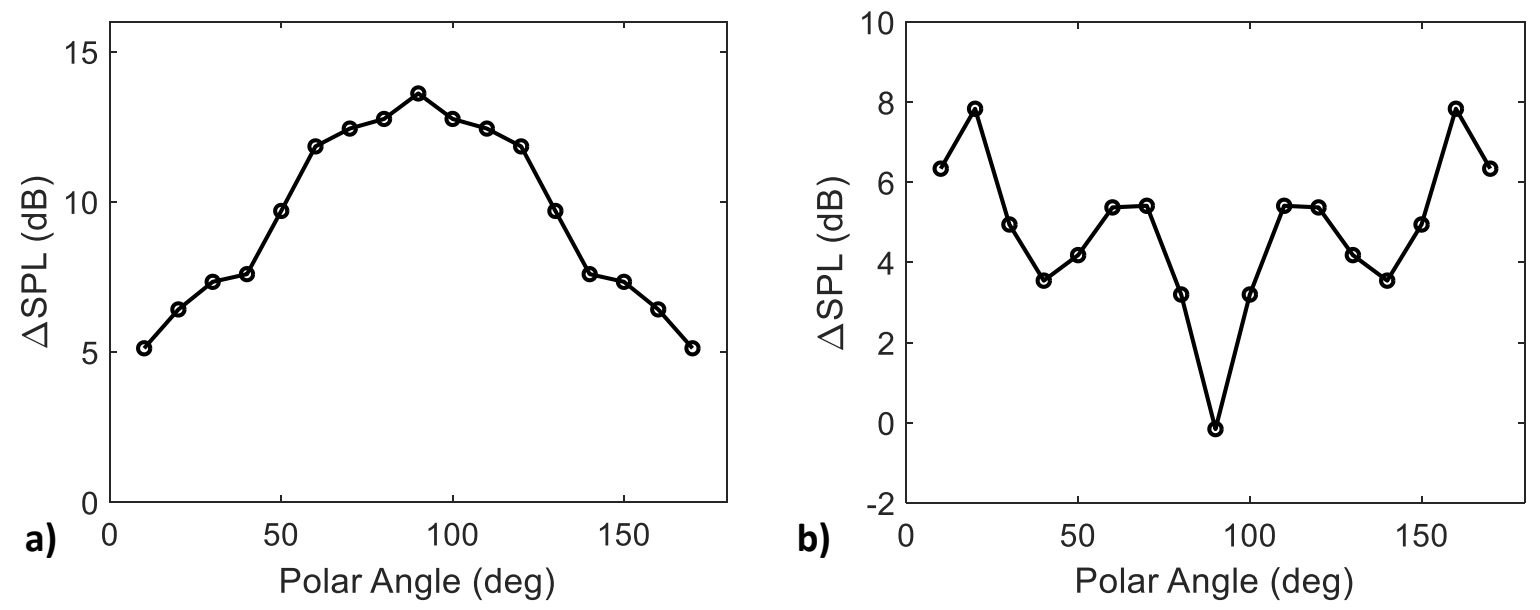

Fig. 7 Acoustic model for the a) tonal and b) broadband effect of turbulence ingestion.

symmetrically upstream and downstream of the fan, while broadband levels increased about $7 \mathrm{~dB}$. The fan used in this experiment was a low-speed, low-pressure-ratio fan with physics unlike those expected for a true turbofan, which may explain the difference in the directivity pattern between this case and the present model. Due to the difference in fan characteristics, these data were not used in generating the model for the present study, but nonetheless serve as a check for the relative magnitudes expected for high levels of inflow distortion. Again, the relative magnitudes of predicted noise levels for the present study are considered reasonable.

\section{Mean Flow Distortion}

The boundary layer developing over the fuselage leads to a region of low-momentum inflow over the lower portion of the fan face. This leads to a once-per-revolution change in incidence angle of the blades as they move through this low-axial-speed region of flow. This change in incidence angle leads to strong unsteady blade loading, which presents acoustically as strong tones at the blade passage frequency and harmonics. Few experiments have been performed which feature this velocity deficit in a fan's inflow, and none include noise measurements. However, if the change in incidence angle over rotation is the focus, an analogous situation is one in which an open rotor is placed at an angle of attack relative to the incoming flow. Geometrically, this creates an angle of attack difference as the advancing blades see a change in inflow relative to the receding blades.

Czech and Thomas [30] tested a counter-rotating open rotor in the Boeing Low Speed Aeroacoustics Facility. Among other tests, the rotor was placed at angles of attack of $0,7,10$, and 13 degrees relative to the incoming flow. At 10 degrees angle of attack, using the blade geometry, flow conditions, and rotational speed of the open rotor, simple geometric calculations indicate that the change in incidence angle of the blades at 70\% span is approximately 4 degrees, which is less than that expected for the ND8 with BLI. However, the data used here represent the best-available information on this effect. Acoustic data are available for a wide range of polar and azimuthal angles, which can be used to build an acoustic model. The forward rotor BPF tone levels are extracted from all angle of attack cases. The zero angle of attack result is subtracted from those of the nonzero angle of attack cases, and the resulting changes in level are averaged to yield a general prediction model for the mean flow distortion effect on the BPF tone shown in Figure 8. It can be seen that this type of effect has the highest influence along the sideline direction.

For the current investigation, the two BLI effects (turbulence ingestion and mean flow distortion) are assumed to be decoupled, which permits the simple summation of the noise models. Once the two tonal effects are summed, the result is a function of both polar and azimuthal angle. The values here were chosen such that they apply to the fundamental $\mathrm{BPF}$ tone. To model the higher harmonics (up to 4BPF), the noise levels are subtracted by $3 \mathrm{~dB}$ for each harmonic to model a decreasing effect of BLI with increasing BPF harmonic. Limited data from Jones et al. [26], Clark et al. [28], and Koch [29] suggest that higher harmonics are affected by nearly the same amount as the fundamental tone, but because these data are more limited and less applicable to the physical scenario at hand, the use of a $3 \mathrm{~dB}$ subtraction for each harmonic represents a conservative choice to predict this effect. 


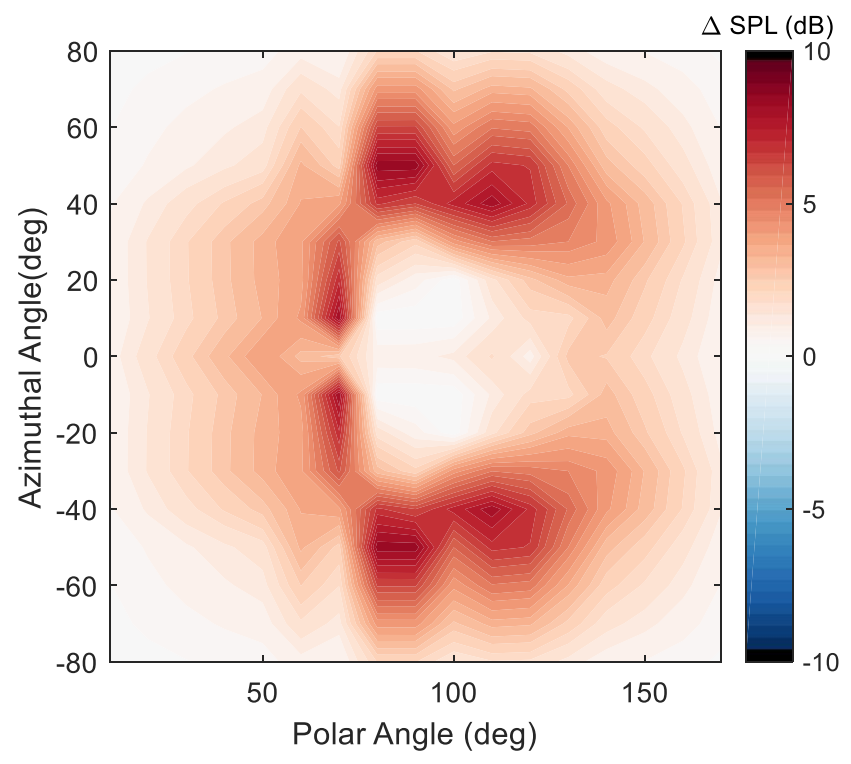

Fig. 8 Acoustic model for the tonal effect of a once-per-revolution change in fan blade incidence angle.

\section{B. Noise Shielding, Reflection, and Diffraction}

The noise scattering effects (shielding, reflection, and diffraction) of the ND8 present a special challenge for system noise modeling. Several features of the ND8 aircraft must be considered to develop a comprehensive model of the engine noise scattering effects. Most evidently, the fuselage structure in front of and below the engines will provide the majority of shielding to the engine inlet at low azimuthal angles (near the flyover plane) and in the forward direction. Importantly, the aft fan nozzles are integrated into the trailing edge of the fuselage and are entirely unshielded, as seen in Figure 9. Just upstream of the engine nacelles, the upper fuselage surface forms two "scoops" which serve to guide the boundary layer flow into the engines. The scoops provide some shielding benefit particularly at sideline angles. On the MIT/Aurora D8 [3], the leading edges of the vertical stabilizers are placed far upstream of the engine inlets, providing a strong noise benefit at sideline. However, this is not true for the ND8 due to a combination of different vertical tail sizes, engine positions, and inlet lengths, which arise from the different modeling assumptions of NASA and MIT/Aurora. As a result, the leading edges are directly adjacent to the engine inlets, as seen in the inset in Figure 4, such that the vertical stabilizers do not provide any shielding benefit. The horizontal stabilizer is placed above and slightly downstream of the engines. This provides a reflecting surface for engine noise to be radiated at aft angles. The spanwise extent of the horizontal stabilizer dictates the level of reflection in the sideline directions.

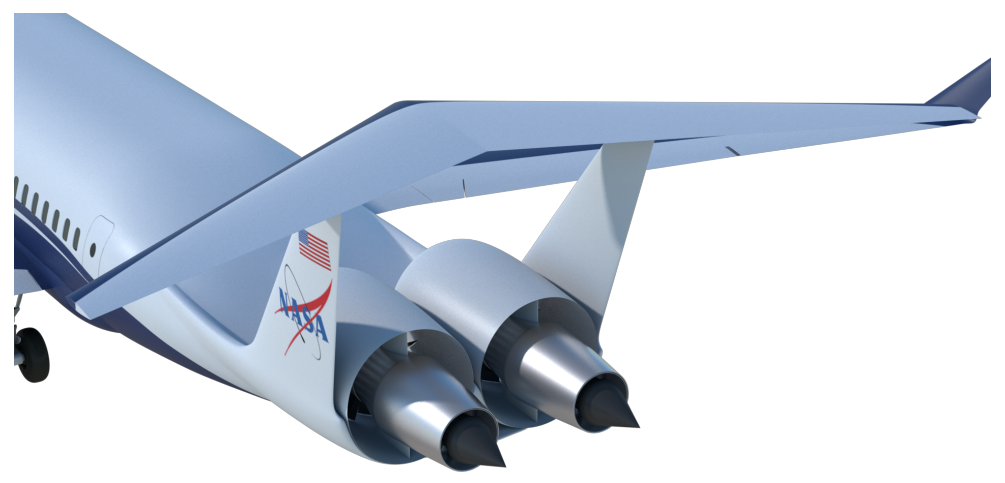

Fig. 9 Closeup rear view of the ND8 tail section. Aft-radiated fan noise is entirely unshielded due to the integration of the fan nacelle with the rear fuselage structure. 
Several experiments have been carried out to quantify acoustic shielding by some airframe configurations, most notably the hybrid wing-body (HWB). PAA experiments by Czech et al. [31] were performed in the Boeing Low Speed Aeroacoustic Facility (LSAF). This experiment featured a broadband noise source inside a nacelle placed at various locations near a hybrid wing-body airframe, with acoustic measurements taken at a wide range of polar and azimuthal angles to quantify the shielding effects of the airframe. The data from these experiments, including many datasets not described in the publications, are used to develop noise shielding maps. Through a unique data processing algorithm, data from these tests are scaled and mapped appropriately to reflect the unique geometric features of the ND8 airframe. As these data are obtained from experiment, they include all effects of shielding and diffraction. Figure 10 shows the results of this process for a single frequency $(1 \mathrm{kHz})$. Shielding of inlet noise by the fuselage is the most prominent feature. Some sideline shielding by the engine scoops is visible, and the reduced levels here reflect the fact that the relatively small, thin scoops will be less effective shields than the full fuselage, and fan noise will diffract around the edges to the sideline angles. Reflection effects are added analytically by computing the specular reflection angles of the engine noise off the pi-tail. Some amplitude loss due to reflection is assumed in the process. These results are applied to both fan noise and core noise, as the locations of these two sources lead to similar shielding characteristics.

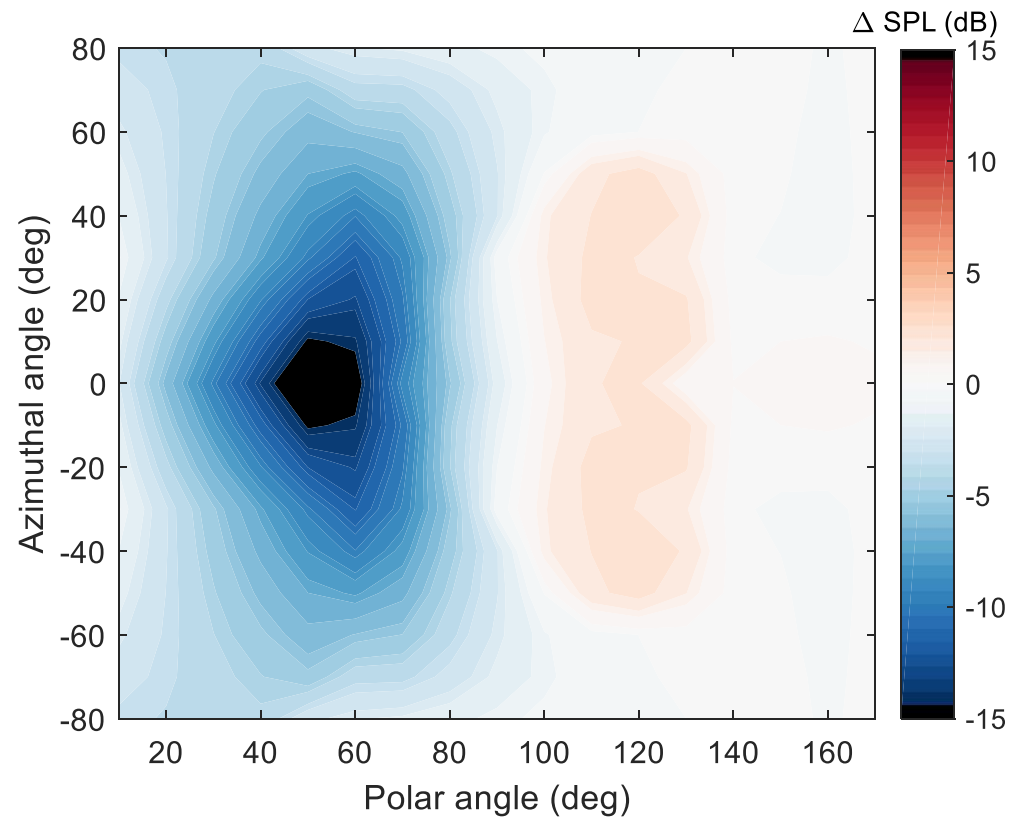

Fig. 10 Scattering effects of the ND8 engine noise by the airframe at $1 \mathrm{kHz}$.

\section{Results and Discussion}

With the methodologies and tools described in previous sections, the noise metrics for the ND8 are calculated and shown in Table 4. The noise of the ND8 was computed with various combinations of boundary layer ingestion and scattering effects included in order to quantify each effect. Results are given as margins to Stage 4 certification levels for consistency with prior publications, as well as published NASA goals. The "baseline" ND8 is first presented. The noise of this non-physical aircraft is computed assuming no PAA effects (no scattering and no BLI). From here, scattering effects are added. Following this, the broadband and tone BLI effects are added separately to quantify the system-level impact of each individual component. Next, scattering effects are removed and all BLI effects are included. Finally, all PAA effects are combined into a complete prediction of the ND8 aircraft.

Considering first the ND8 with no PAA effects, the cumulative margin to Stage 4 is 20.5 EPNdB. When scattering effects are added, the margin increases to $22.4 \mathrm{EPNdB}$. Most of this benefit is obtained at the approach certification point, where forward-radiated fan noise plays the most significant role. At sideline, reduced shielding leads to less of an impact on EPNL levels. At cutback, lack of aft shielding and the dominance of aft-radiated fan noise, together with reflections from the tail, cancel out the benefit of forward shielding. When BLI effects are included, noise levels are drastically increased. With both broadband and tone effects included, levels are increased 16.1 EPNdB above the 
Table 4 Certification levels (EPNdB) for each ND8 configuration.

\begin{tabular}{lcccccc}
\hline PAA Effects Included & Approach & Sideline & Cutback & Cumulative & $\begin{array}{c}\text { Margin to } \\
\text { Stage 4 }\end{array}$ & $\begin{array}{c}\text { Noise Increase } \\
\text { from Baseline }\end{array}$ \\
None (Baseline) & 86.8 & 87.6 & 82.0 & 256.4 & 20.5 & - \\
Scattering & 85.6 & 86.9 & 82.0 & 254.5 & 22.4 & -1.9 \\
Scattering and Broadband BLI & 87.3 & 89.3 & 85.0 & 261.6 & 15.3 & 5.2 \\
Scattering and Tone BLI & 87.5 & 92.6 & 86.8 & 266.9 & 10.0 & 10.5 \\
All BLI & 90.3 & 94.2 & 88.0 & 272.5 & 4.4 & 16.1 \\
All PAA & 88.4 & 93.4 & 87.7 & 269.5 & 7.4 & 13.1 \\
\hline
\end{tabular}

baseline configuration. Shielding moderates this increase by $3 \mathrm{EPNdB}$, again having most influence at approach, leading to a final cumulative margin to Stage 4 of 7.4 EPNdB.

With scattering effects held constant, the tonal BLI effect is seen to have twice the influence as the broadband BLI effect. This is because of the greater magnitude of tonal levels predicted for BLI, in addition to the fact that increased tonal levels have a two-fold effect on computed EPNL. Not only do greater tones increase the absolute magnitude of the received noise, but they also increase the computed tone penalty of the tone-corrected perceived noise level, which is then integrated to obtain EPNL. The effect of BLI on tones was modeled based on the BPF harmonics of the fan, which is dependent on operating condition (fan RPM). At sideline (full throttle setting), the BPF tone is placed in the 1-kHz one-third-octave band, with the higher harmonics affected by BLI placed in the 2-, 3-, and 4-kHz bands. The frequency range from 2- to $4-\mathrm{kHz}$ is the highest-weighted frequency range for calculating perceived noise level. As a result, the greater tones here are particularly effective at increasing EPNL. At cutback, the tones are slightly reduced in frequency, but only at the approach condition do the first three harmonics fall below $2 \mathrm{kHz}$. This leads to reduced influence of BLI on approach certification levels - with scattering effects, the complete BLI effect yields a 2.8 EPNdB increase, compared to $6.5 \mathrm{EPNdB}$ and $5.7 \mathrm{EPNdB}$ increases at sideline and cutback, respectively.

Figures 11 through 13 show tone-corrected perceived noise levels with and without BLI effects at each of the three certification points. Several key observations can be extracted from these plots that lead to greater understanding of the ND8 noise characteristics. The first observation is the clear dominance of fan noise at all certification points, even when no BLI effects are included. This shows that fan noise is the primary driver of EPNL. The situation is only made worse by the BLI effects, which lead to such a high dominance of fan noise that other noise sources contribute almost nothing to overall EPNL levels. It is thus apparent that the feasibility of the ND8 as a quiet aircraft is first dependent on the control of BLI noise, followed by additional modifications to further reduce fan noise. It is anticipated that the noise penalty associated with BLI could be controlled through careful design of the propulsion system. For example, a boundary layer suction system could remove much of the flow distortion, leading to a smoother flow into the fan. Such a system would only be used near the ground, as its use would negate the expected fuel burn benefit associated with boundary layer ingestion.

Assuming the inflow distortion could be controlled, it is useful to examine the PNLT plots without boundary layer ingestion to gain further insight into how noise could be further reduced. Considering first the approach levels in Figure 11, the influence of forward shielding by the fuselage is immediately apparent. Fan noise is sufficiently reduced in the forward arc for airframe sources to contribute significantly to EPNL. In particular, the flap, slat, and main gear are all seen to have similar noise levels that are higher than fan noise until the lack of aft shielding again leads to dominance of fan noise. Nose gear, jet, core, and trailing edge noise are insignificant here. At the sideline condition (again, without BLI), jet and fan noise play a nearly equal role in determining EPNL levels. These noise sources could be reduced by utilizing a higher bypass-ratio engine. Ultra-high-bypass ratios up to 25 are expected to be available in the 2035 time frame [15], but the physical constraints on maximum engine diameter imposed by the pi-tail again limit the current configuration to a bypass ratio of 16 . Fan noise could also be reduced somewhat by modification of the vertical stabilizers to provide more sideline shielding. Finally, at cutback, fan noise peaks at a level approximately 7 $\mathrm{dB}$ above jet noise. Dominance of aft-radiated fan noise, along with reflections by the pi-tail, are the primary factors contributing to cutback EPNL. Few options are available to increase aft-radiated fan noise shielding, but modifications to the pi-tail could reduce or eliminate reflections.

Even if inflow distortion is well controlled such that BLI noise is eliminated, the ND8's cumulative margin to Stage 4 of only 22.4 EPNdB falls well short of the NASA Mid Term goal of 32-42 EPNdB. As a final point of comparison, 

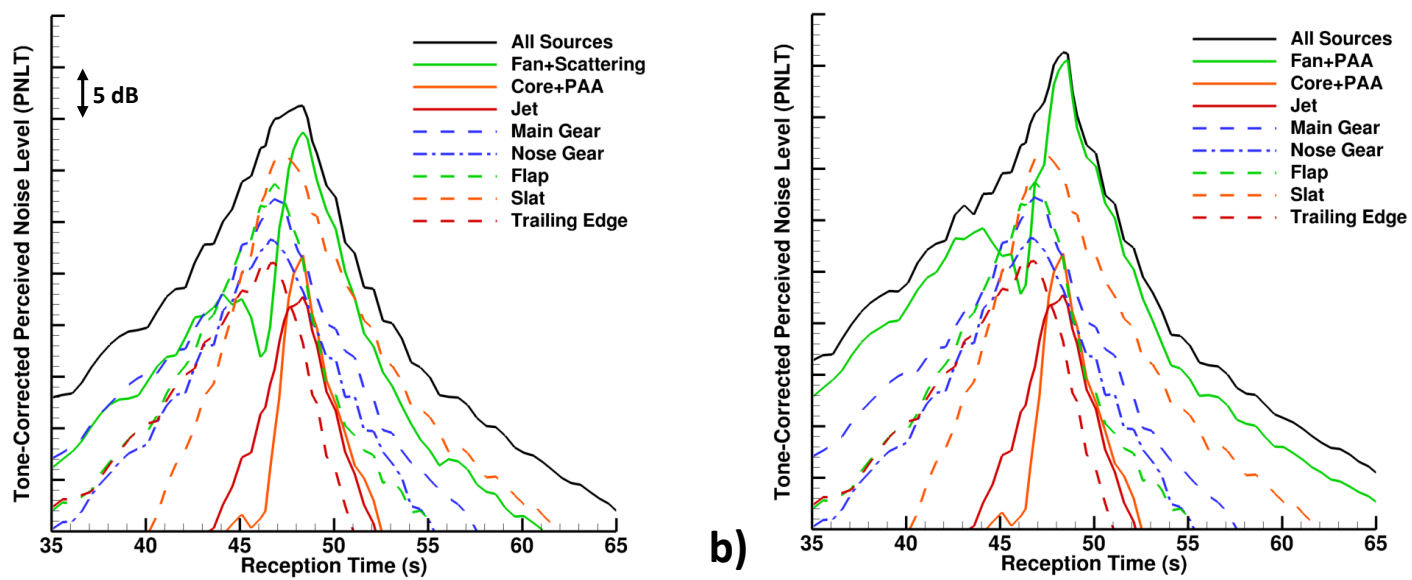

Fig. 11 ND8 source levels calculated over reception time as the aircraft flies past the approach certification point a) without and b) with BLI effects.
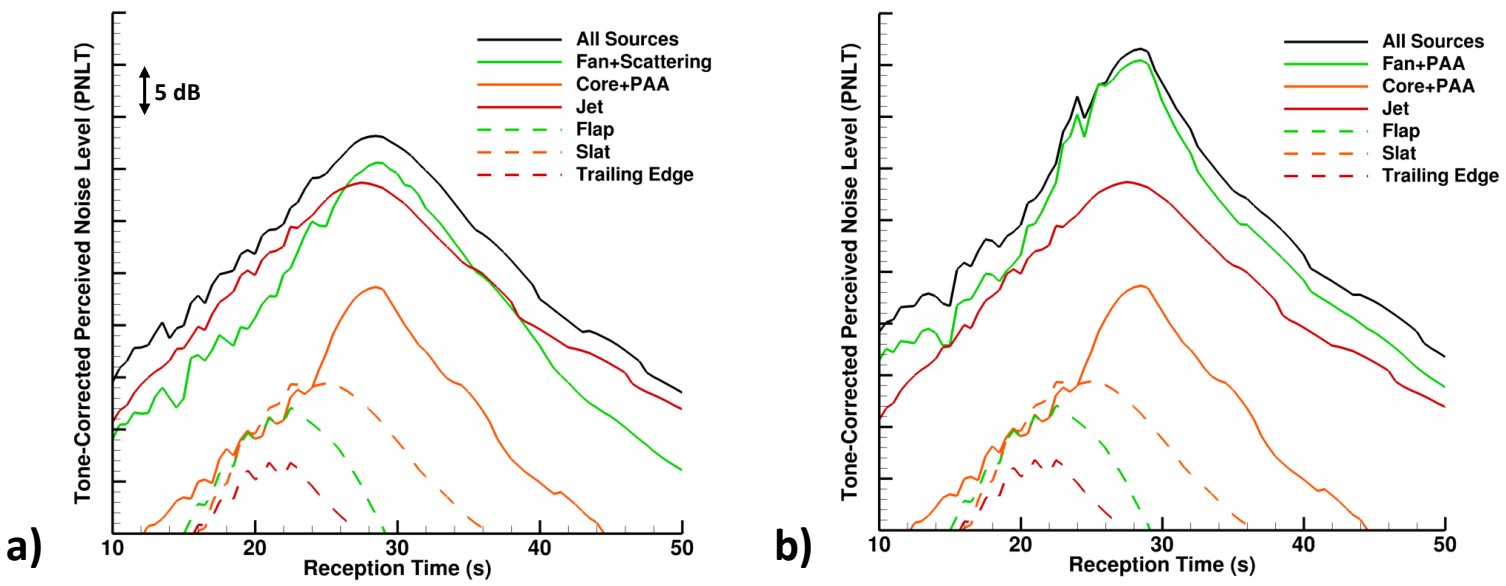

Fig. 12 ND8 source levels calculated over reception time as the aircraft flies past the sideline certification point a) without and b) with BLI effects.

the T+W160 concept assessed by Thomas et al. [17] was predicted to reach a margin to Stage 4 of $31.4 \mathrm{EPNdB}$. It is important to note here that the prediction methods used to predict the ND8 have been updated since the T+W160 result was published, but nonetheless, this offers some insight into the acoustic performance of the ND8. The decreased bypass ratio is expected to be responsible for the majority of the difference, as this leads to a supersonic fan tip Mach number at sideline, compared to the subsonic fan tip Mach number of the larger T+W160 engine. The lower bypass ratio of the ND8, together with the dominance of aft-radiated fan noise, reduced climb performance, and similar PAA effects (aft reflections from the tail and wing for the ND8 and T+W160, respectively), lead to higher noise levels than the T+W160. For the ND8 to reach NASA Mid Term goals, the tail section must be redesigned to accommodate higher bypass ratio engines and to provide more side and aft shielding, although a redesign of this magnitude may be incompatible with the boundary layer ingestion feature that is critical to the fuel burn goal. It is expected that multidisciplinary design and analysis may be necessary to determine if a future iteration of the ND8 could be a viable candidate to meet the NASA Mid Term goals for fuel burn and noise simultaneously. 

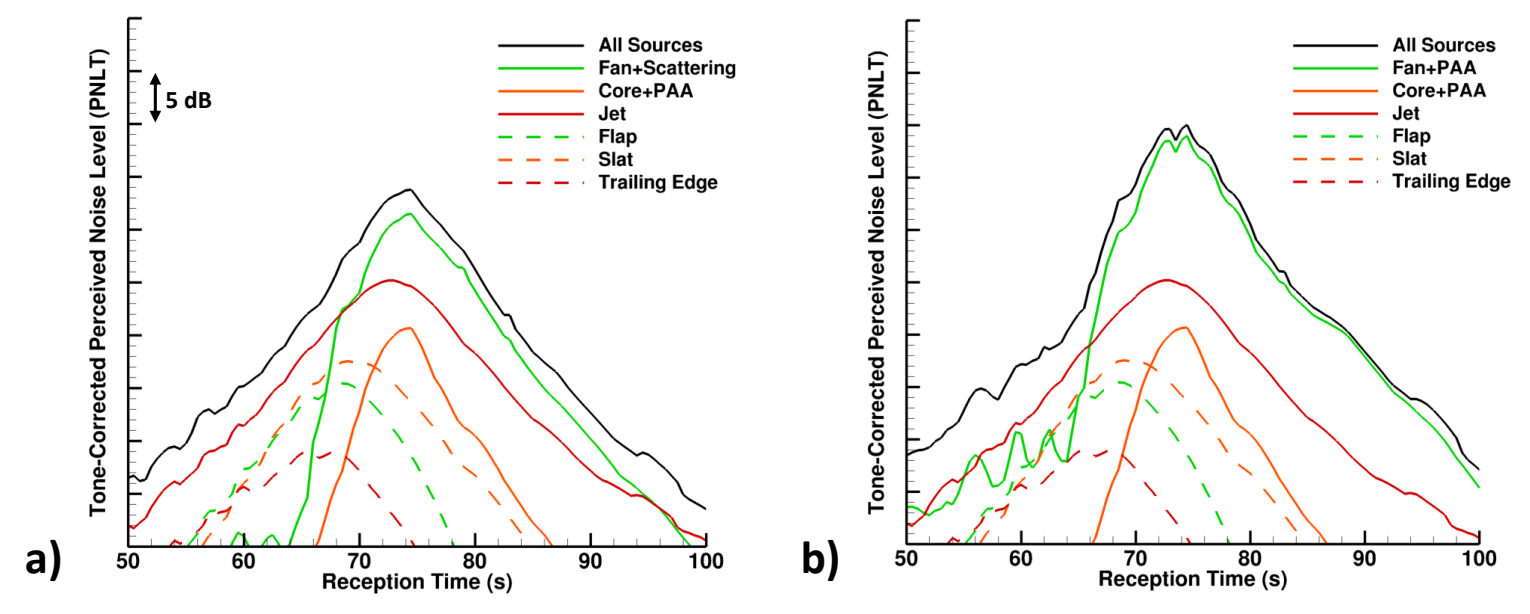

Fig. 13 ND8 source levels calculated over reception time as the aircraft flies past the cutback certification point a) without and b) with BLI effects.

\section{Summary}

A comprehensive noise assessment of the NASA D8 concept aircraft has been performed using the NASA researchlevel Aircraft NOise Prediction Program (ANOPP-Research). This version of ANOPP is well-suited to unconventional aircraft configurations and so provides a strong basis for this noise assessment. The airframe and engine designs of the ND8 were optimized for minimum fuel burn, and this overall design was used without modification for the system noise assessment. Noise reduction technologies and detailed design components appropriate to the 2035 entry-into-service date were assumed. The propulsion-airframe aeroacoustic (PAA) effects of the ND8 were seen to be the defining features in terms of noise. The acoustic effect of boundary layer ingestion, which is included primarily for fuel burn benefit, was modeled using data from several experiments that featured key physical phenomena - turbulence ingestion and a once-per-revolution variation in fan blade incidence angle. These experiments were chosen because they typically featured turbofans with realistic speeds and pressure ratios. The BLI acoustic model was compared with the results of other studies with turbulence ingestion, but with less realistic fans. The results compared well on a qualitative basis. The scattering effects (shielding, reflection, and diffraction) were quantified using data from prior experiments, and mapped to reflect the unique geometry of the ND8.

When all Mid Term noise reduction technologies (porous flap side edge, partial main gear fairing, MDOF liner, and soft vane) and PAA effects are included, the ND8 is predicted to have a cumulative margin to Stage 4 certification levels of only 7.4 EPNdB. Boundary layer ingestion is predicted to have a roughly $15 \mathrm{EPNdB}$ noise penalty on cumulative certification noise. The majority of this effect comes from the sideline point, where engines are at full throttle for takeoff. Due to the rotational speed and number of fan blades, the blade passage frequency and harmonics are placed in the 1-4 kHz range where spectral levels have the most influence on tone-corrected perceived noise level (PNLT) and, by extension, EPNL. The strong tone levels expected due to BLI also result in an additional tone-penalty beyond the base increase in source level.

If BLI noise is entirely suppressed, the cumulative margin to Stage 4 is 22.4 EPNdB. The shielding benefit achieved by engine placement is limited by the dominance of unshielded aft-radiated fan noise, particularly at the cutback condition. Reflections from the horizontal tail also contribute to noise in the aft region. The fuselage structure just upstream of the engines does provide some shielding benefit at sideline, but again this benefit is limited to forward angles. Further reduction of fan noise would require the addition of more aggressive noise reduction technologies or reconfiguration of the tail layout to accommodate higher bypass ratio engines. 


\section{Acknowledgments}

The support of the Aircraft Noise Reduction Subproject of the Advanced Air Transport Technology Project is gratefully acknowledged. The authors would like to thank Jason June, John Rawls, and Stuart Pope of the Aircraft System Noise/PAA Team of the Aeroacoustics Branch at NASA Langley Research Center for contributing to this study. The engine definition was provided by Scott Jones and Jeff Berton of the Propulsion Systems Analysis Branch at NASA Glenn Research Center. The airframe and flight path definition were provided by Ty Marien of the Aeronautics Systems Analysis Branch at NASA Langley Research Center. Artist renderings of the ND8 aircraft and engine were provided by Eric Fay, Joshua Sams, and Jonathan Levy of the Advanced Concepts Laboratory, Analytical Mechanics Associates.

\section{References}

[1] Greitzer, E. M., Bonnefoy, P. A., De la Rosa Blanco, E., Dorbian, C. S., Drela, M., Hall, D. K., Hansman, R. J., Hileman, J. I., Liebeck, R. H., Lovegren, J., Mody, P., Pertuze, J. A., Sato, S., Spakovszky, Z. S., Tan, C. S., Hollman, J. S., Duda, J. E., Fitzgerald, N., Houghton, J., Kerrebrock, J. L., Kiwada, G. F., Kordonowy, D., Parrish, J. C., Tylko, J., Wen, E. A., and Lord, W. K., "N + 3 Aircraft Concept Designs and Trade Studies , Final Report Volume 1," NASA/CR-2010-216794/VOL1, 2010.

[2] Drela, M., "Development of the D8 Transport Configuration," 29th AIAA Applied Aerodynamics Conference, Honolulu, Hawaii, 2011. doi:10.2514/6.2011-3970.

[3] Yutko, B. M., Jeffrey, C. T., Church, C. S., Courtin, C., Lieu, M., Roberts, T. W., and Titchener, N., "Conceptual Design of a D8 Commercial Aircraft," 17th AIAA Aviation Technology, Integration, and Operations Conference, Denver, Colorado, 2017. doi:10.2514/6.2017-3590.

[4] Hill, G., and Thomas, R., "Challenges and Opportunities for Noise Reduction Through Advanced Aircraft Propulsion Airframe Integration and Configurations," 8th CEAS Workshop on Aeroacoustics of New Aircraft and Engine Configurations, Budapest, Hungary, 2004.

[5] Chambers, J. T., Yutko, B. M., Singh, R., and Church, C., "Structural Optimization Study of the D8 Double-Bubble Composite Fuselage," 58th AIAA/ASCE/AHS/ASC Structures, Structural Dynamics, and Materials Conference, Grapevine, Texas, 2017. doi:10.2514/6.2017-0508.

[6] Marien, T. V., Welstead, J. R., and Jones, S. M., "Vehicle Level System Impact of Boundary Layer Ingestion for the NASA D8 Concept Aircraft," AIAA SciTech Forum - 56th AIAA Aerospace Sciences Meeting, Kissimmee, Florida, 2018. doi:10.2514/6.2018-0271.

[7] Pandya, S. A., "Computational Assessment of the Boundary Layer Ingesting Nacelle Design of the D8 Aircraft," AIAA SciTech Forum - 52nd Aerospace Sciences Meeting, National Harbor, Maryland, 2014. doi:10.2514/6.2014-0907.

[8] De la Rosa Blanco, E., and Hileman, J. I., "Noise Assessment of the Double-Bubble Aircraft Configuration," 49th AIAA Aerospace Sciences Meeting, Orlando, Florida, 2011. doi:10.2514/6.2011-268.

[9] Preisser, J. S., and Chestnutt, D., "Flight Effects on Fan Noise with Static and Wind-Tunnel Comparisons," Journal of Aircraft, Vol. 21, No. 7, 1984, pp. 453-461. doi:10.2514/3.44993.

[10] Alexander, W. N., Devenport, W. J., Wisda, D., Morton, M. A., and Glegg, S. A., "Sound Radiated From a Rotor and Its Relation to Rotating Frame Measurements of Ingested Turbulence," 20th AIAA/CEAS Aeroacoustics Conference, Atlanta, Georgia, 2014. doi:10.2514/6.2014-2746.

[11] Wisda, D., Alexander, W. N., Devenport, W. J., and Glegg, S. A., "Boundary Layer Ingestion Noise and Turbulence Scale Analysis at High and Low Advance Ratios," 20th AIAA/CEAS Aeroacoustics Conference, Atlanta, Georgia, 2014. doi:10.2514/6.2014-2608.

[12] Guo, Y., Burley, C. L., and Thomas, R. H., "Landing Gear Noise Prediction and Analysis for Tube-And-Wing and Hybrid-WingBody Aircraft," 54th AIAA Aerospace Sciences Meeting, San Diego, California, 2016. doi:10.2514/6.2016-1273.

[13] Guo, Y., Burley, C. L., and Thomas, R. H., "Modeling and Prediction of Krueger Device Noise," 22nd AIAA/CEAS Aeroacoustics Conference, Lyon, France, 2016. doi:10.2514/6.2016-2957.

[14] Thomas, R. H., Guo, Y., Berton, J., and Fernandez, H., “Aircraft Noise Reduction Technology Roadmap Toward Achieving The NASA 2035 Goal,” 23rd AIAA/CEAS Aeroacoustics Conference, Denver, Colorado, 2017. doi:10.2514/6.2017-3193. 
[15] Nickol, C. L., and Haller, W. J., "Assessment of the Performance Potential of Advanced Subsonic Transport Concepts for NASA's Environmentally Responsible Aviation Project," AIAA SciTech Forum - 54th AIAA Aerospace Sciences Meeting, San Diego, California, 2016. doi:10.2514/6.2016-1030.

[16] "Design Considerations for Minimizing Hazard Caused by Uncontained Turbine Engine and Auxiliary Power Unit Rotor Failure," Federal Aviation Administration Advisory Circular 20-128A, 1997.

[17] Thomas, R. H., Burley, C. L., and Nickol, C. L., "Assessment of the Noise Reduction Potential of Advanced Subsonic Transport Concepts for NASA's Environmentally Responsible Aviation Project," AIAA SciTech Forum - 54th AIAA Aerospace Sciences Meeting, San Diego, California, 2016. doi:10.2514/6.2016-0863.

[18] Khorrami, M. R., Humphreys, W. M., Lockard, D. P., and Ravetta, P. A., “Aeroacoustic Evaluation of Flap and Landing Gear Noise Reduction Concepts,” 20th AIAA/CEAS Aeroacoustics Conference, 2014. doi:10.2514/6.2014-2478.

[19] Fares, E., Casalino, D., and Khorrami, M. R., "Evaluation of Airframe Noise Reduction Concepts via Simulations Using a Lattice Boltzmann Approach," 21th AIAA/CEAS Aeroacoustic Conference and Exhibit, Dallas, Texas, 2015. doi:10.2514/6.2015-2988.

[20] Majumdar, S. J., and Peake, N., "Noise generation by the interaction between ingested turbulence and a rotating fan," Journal of Fluid Mechanics, Vol. 359, 1998, pp. 181-216. doi:10.1017/S0022112097008318.

[21] Glegg, S. A. L., Devenport, W., and Alexander, N., "Broadband rotor noise predictions using a time domain approach," Journal of Sound and Vibration, Vol. 335, 2015, pp. 115-124. doi:10.1016/j.jsv.2014.09.007.

[22] Envia, E., "Acoustic Power Transmission Loss Through A Ducted Fan," 22nd AIAA/CEAS Aeroacoustics Conference, Lyon, France, 2016. doi:10.2514/6.2016-3064.

[23] Verdon, J. M., "Linearized Unsteady Aerodynamic Analysis of the Acoustic Response to Wake / Blade-Row Interaction," Tech. rep., NASA/CR-2001-210713, 2001.

[24] Uranga, A., Drela, M., Greitzer, E. M., Titchener, N. A., Lieu, M. K., Siu, N. M., Huang, A. C., Gatlin, G. M., and Hannon, J. A., "Preliminary Experimental Assessment of the Boundary Layer Ingestion Benefit for the D8 Aircraft," AIAA SciTech Forum - 52nd Aerospace Sciences Meeting, National Harbor, Maryland, 2014. doi:10.2514/6.2014-0906.

[25] Hanson, D. B., "Spectrum of Rotor Noise Caused by Atmospheric Turbulence," The Journal of the Acoustical Society of America, Vol. 56, No. 1, 1974, pp. 110-126. doi:10.1121/1.1903241.

[26] Jones, W. L., McArdle, J. G., and Homyak, L., "Evaluation of Two Inflow Control Devices for Flight Simulation of Fan Noise Using a JT15D Engine," 5th Aeroacoustics Conference, Seattle, Washington, 1979.

[27] “Flight effects of fan noise," NASA Conference Publication 2242, edited by D. Chestnutt, 1982.

[28] Clark, L., Thomas, R., Dougherty, R., Farassat, F., and Gerhold, C., "Inlet shape effects on the far-field sound of a model fan," 3rd AIAA/CEAS Aeroacoustics Conference, Atlanta, Georgia, 1997. doi:10.2514/6.1997-1589.

[29] Koch, L., “An Experimental Study of Fan Inflow Distortion Tone Noise," 15th AIAA/CEAS Aeroacoustics Conference (30th AIAA Aeroacoustics Conference), Miami, Florida, 2009. doi:10.2514/6.2009-3290.

[30] Czech, M. J., and Thomas, R. H., "Open Rotor Aeroacoustic Installation Effects for Conventional and Unconventional Airframes," AIAA Aeroacoustics Conference, Berlin, Germany, 2013. doi:10.2514/6.2013-2185.

[31] Czech, M. J., Thomas, R. H., and Elkoby, R., "Propulsion Airframe Aeroacoustic Integration Effects for a Hybrid Wing Body Aircraft Configuration," International Journal of Aeroacoustics, Vol. 11, No. 3-4, 2012, pp. 335-367. doi:10.1260/1475472X.11.3-4.335. 